\title{
PROPOSTA DE ESTRATÉGIA DIDÁTICA COM A UTILIZAÇÃO DE JOGOS COMPUTACIONAIS NO ENSINO DE QUÍMICA
}

\author{
Apresentação: Pôster
}

Richardson Robério da Silva ${ }^{1}$; Arthur Fernandes da Rocha Pimentel ${ }^{2}$; Cláudio Felipe Souza Fonseca ${ }^{3}$; Marília Gabriela Menezes Guedes ${ }^{4}$.

\section{Introdução}

Neste trabalho temos como objetivo apresentar estratégias didáticas no ensino de química para as turmas de Ensino Médio utilizando os recursos tecnológicos, sendo assim propomos o uso de jogos computacionais na área de química que estimulem o aprendizado dos(as) estudantes e que apresentem uma nova perspectiva de didáticas a serem aplicadas em sala de aula.

\section{Fundamentação Teórica}

O ensino da química no Brasil vem sendo um grande desafio, pois a crescente desmotivação dos(as) estudantes em aprender os conteúdos ensinados tem se tornado cada vez mais evidente. Dentre os fatores que justificam esse comportamento dos(as) estudantes destacamos o nível de abstração de alguns conteúdos dessa área do conhecimento como, por exemplo, a estequiometria de reações e a teoria atômica. Esta realidade aponta para a necessidade de construção de novas estratégias didáticas para o ensino de química que possibilite melhor compreensão do conteúdo químico (CARDOSO; COLINVAUX, 2000).

Nessa direção, de acordo com Schnetzler (2002) o uso da tecnologia como recurso didático é uma ferramenta interessante, pois além de oferecer a possibilidade de materializar alguns conteúdos abstratos, sua utilização proporciona mais conforto para os(as) estudantes

\footnotetext{
${ }^{1}$ Licenciatura em Química, UFPE, richardson.roberio@gmail.com.

${ }^{2}$ Licenciatura em Química, UFPE, arthurfernandes_@ hotmail.com

${ }^{3}$ Licenciatura em Química, UFPE, claudiofelipe122@gmail.com

${ }^{4}$ Doutorado em Educação, UFPE, mariliagabrielaufpe@gmail.com.
} 
devido à familiarização que eles(as) têm com esses recursos. Isso faz com que a aprendizagem torne-se mais lúdica e desafiadora permitindo maior envolvimento dos(as) estudantes.

\section{Metodologia}

Inicialmente realizamos uma pesquisa no site da Universidade do Colorado $^{1}$ que possui trinta e nove (39) jogos computacionais disponíveis para download que abordam conteúdos de química. Selecionamos quatro (4) jogos com base nos conteúdos em que os(as) estudantes possuem maior dificuldade, sendo eles:concentration;density;acid-basesolutions e reactants, productsandleftovers.

O jogo concentration tem por objetivo esclarecer quais são os fatores que afetam a concentração de soluções. Apresenta de forma visual os componentes de uma solução (solvente e soluto) e como a adição ou remoção de um destes afeta a concentração. A sua interface gráfica traz um béquer de 1 litro graduado, uma torneira acima do béquer, onde pode-se adicionar o solvente (água), fazendo-se a concentração diminuir; uma torneira conectada a parte inferior do béquer, de onde pode-se eliminar a solução e chegar a conclusão de que a concentração não varia ao se fazer isso; um frasco com o soluto, que pode ser agitado de forma a permitir a adição do soluto ao béquer, o que aumenta a concentração; um sensor para medição da concentração e suas variações e uma opção de evaporação, no qual é possível visualizar a evaporação do solvente, o que acarreta no aumento da concentração (Figura 1).

Figura 1: Interface gráfica do jogo de simulação concentration.

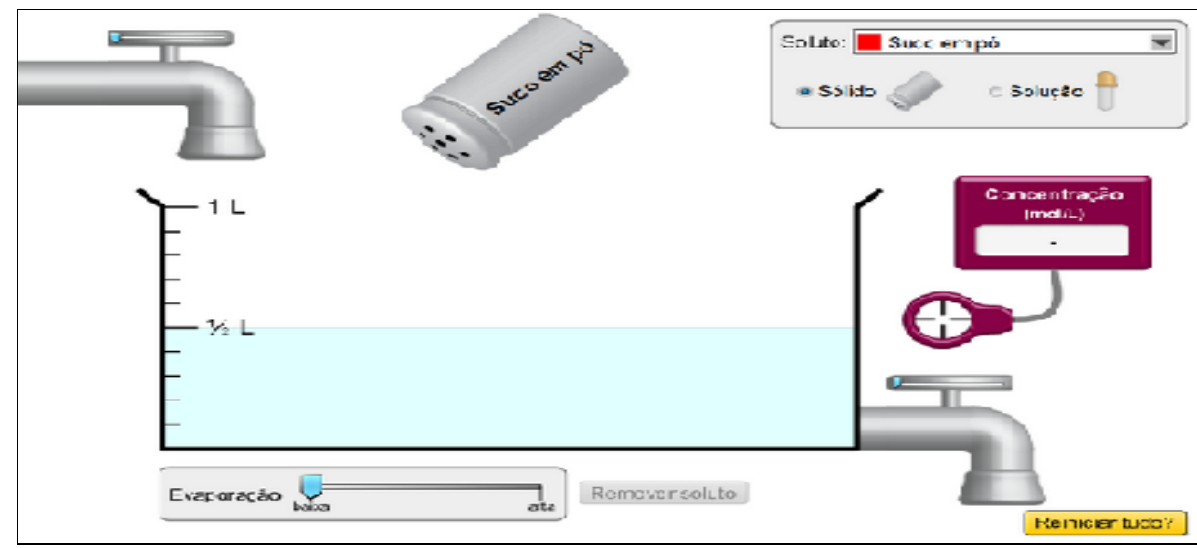

Fonte: foto retirada pelos autores, 2014.

O density é um jogo que trabalha o conceito de densidade. Sua interface traz blocos de vários tamanhos, que podem ser feitos de materiais diferentes; uma piscina com um volume 
fixo de água e algumas ferramentas adicionaiscomo uma balançaque serve para medir a massa dos blocos. Nele, também há uma opção, "mistério", onde tem-se blocos de tamanhos variados e não se sabe a massa deles, porém pode-se pesá-los na balança e obter seus volumes submergindo-os na piscinasem soltá-losverificando a variação do volume de água. Ao obterse o volume dos dados, pode-se efetuar o cálculo da densidade do bloco e julgar se ele flutua ou submerge na água.Um corpo flutua se sua densidade for menor que a densidade da água (1 $\mathrm{g} / \mathrm{cm} 3$ ) ou submerge se a densidade for maior (Figura 2).

Figura 2: Interface gráfica do jogo de simulaçãodensity.

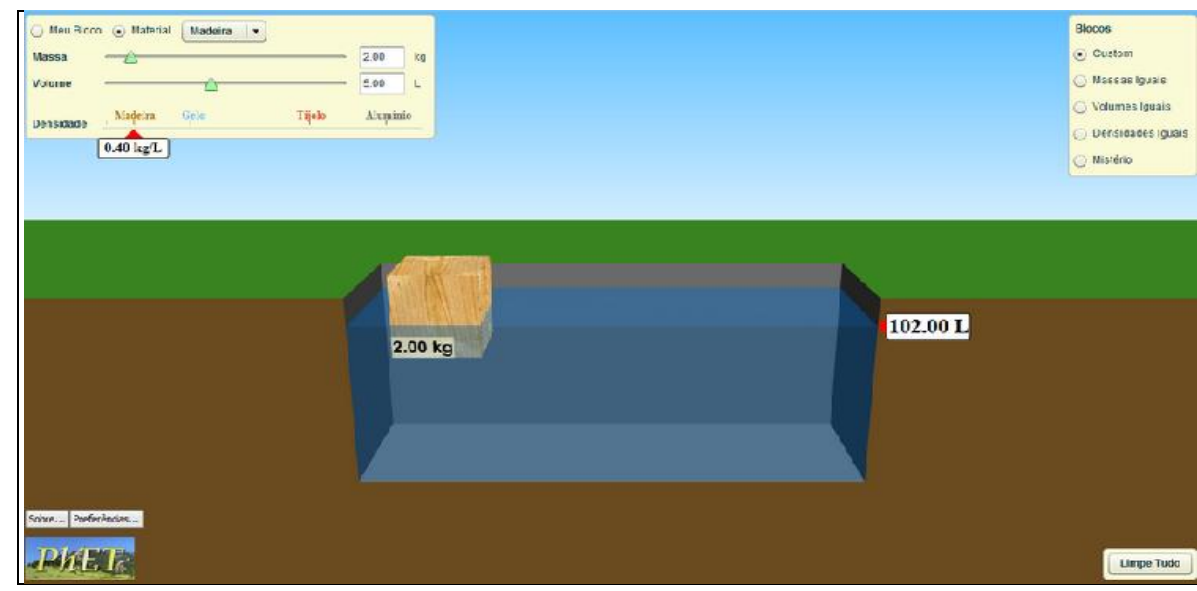

Fonte: foto retirada pelos autores, 2014.

O jogo acid-basesolutionsobjetiva esclarecer sobre o conceito de $\mathrm{PH}$ e os fatores que contribuem para a condução de corrente elétrica. Na sua interface é possível a visualização dos íons (OH- e H+) que afetam o pH em uma solução. Tem-se opções de aumentar ou diminuir a quantidade desses íons, o que faz com que se evidencie a diferença entre ácidos/bases fortes e ácidos/bases fracas. O jogo também mostra qual solução conduz melhor a eletricidade. Todas essas dinâmica favorece para que os(as) estudantes entendam o conceito de pH ácido e básico e as justificativas de algumas soluções conduzirem eletricidade melhor do que outras (Figura 3). 
Figura 3: Interface gráfica do jogo de simulaçãoacid-basesolutions

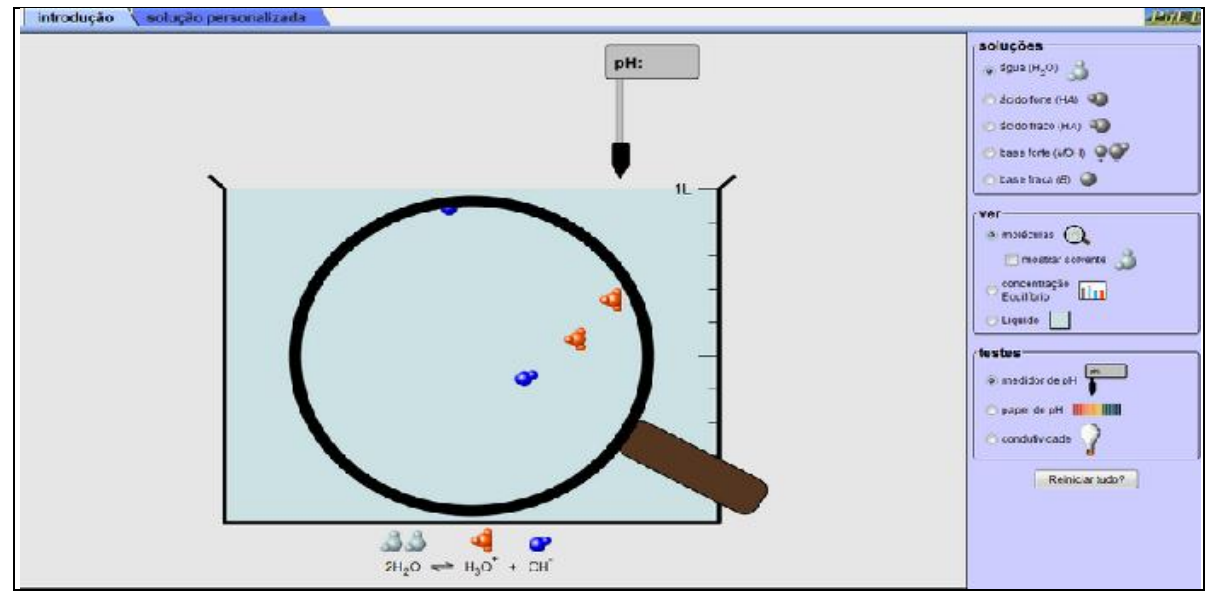

Fonte: foto retirada pelos autores, 2014.

O reactantsproductsandleftovers é um jogo que aborda os assuntos de estequiometria e balanceamento de equações químicas. Em sua interface é possível perceber a presença de produtos em excesso, o que aumenta a utilidade do software, pois além de se trabalhar o balanceamento das reações, através dos produtos fornecidos corretamente na solução, trabalha-se este processo levando-se em conta os excessos formados. O jogo traz uma série de equações químicas, em três níveis, para que sejam feitos os balanceamentos, onde ao final a pontuação atingida pelo jogador é mostrada. A aplicação desse jogo torna-se muito importante devido a dificuldade que muitos estudantes possuem a respeito de estequiometria e, principalmente, balanceamento de equações (Figura 4).

Figura 4: Interface gráfica do jogo de simulaçãoreactantsproductsandleftovers

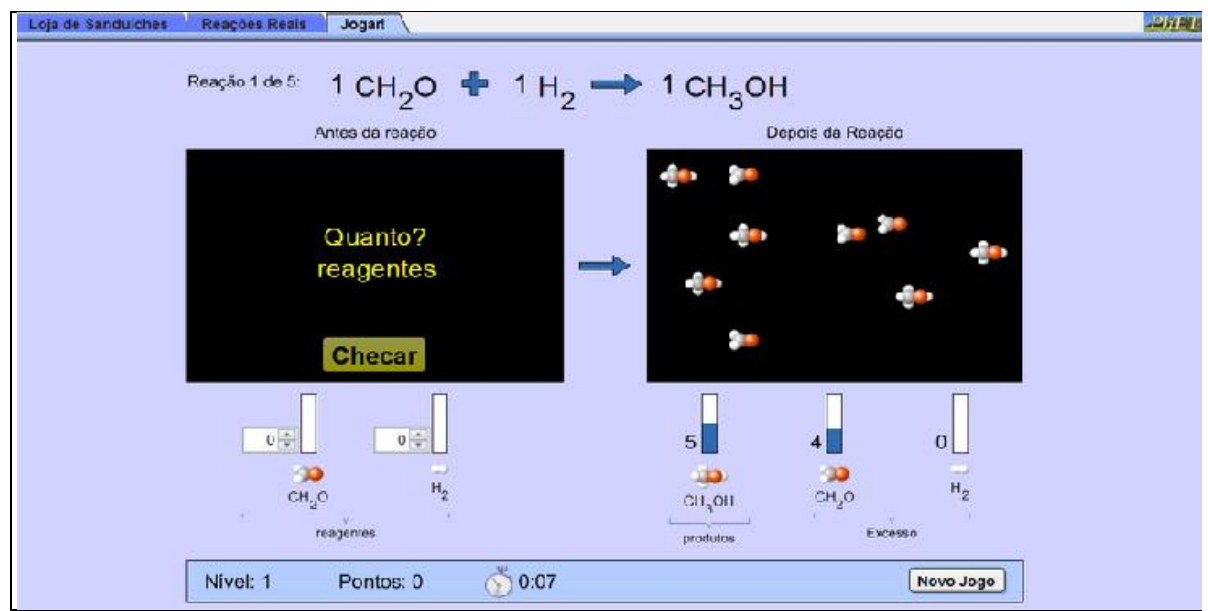

Fonte: foto retirada pelos autores, 2014. 
Para aplicar os jogos computacionais em sala de aula, propomos a apresentação delesaos(as) estudantes, explicando o funcionamento de cada um com a discussão dos conteúdos. Como cada jogo aborda um contexto diferente, ao final de cada aula, o(a) professor(a) pode sistematizar o conteúdo a partir das informações que os jogos oferecem e dos questionamentos dos(as) estudantes a experiência vivenciada.

\section{Considerações finais}

Os jogos computacionais selecionados se referem a assuntos específicos de modo interativo, o que permite melhor visualização dos conceitos químicos, sendo assim esperamos que ao proporcionar aos(as) estudantes do Ensino Médio estas atividades utilizando os recursos tecnológicos com os quais possuem familiaridade, eles(as)possam desenvolvermaior interesse pelo aprendizado dos conteúdos de química com maior participação nas aulas uma vez que essas atividades superaram as aulas expositivas, assim como compreendam melhor o conteúdo e percebam outras formas para melhor utilizar as ferramentas queeles(as) têm disponíveis para os estudos.

\section{Referências}

CARDOSO, Sheila Pressentin; COLINVAUX, Dominique. Explorando a motivação para estudar química, Química nova, v. 23, p. 401-404, 2000.

SCHNETZLER, Roseli P. A pesquisa em ensino de química no Brasil: Conquistas e perspectivas, Química nova, vol. 25, p. 14-24, 2002.

\section{Nota}

${ }^{1}$ Site da Universidade do Colorado, onde os jogos estão disponíveis para download: http://phet.colorado.edu/en/simulations/category/chemistry. 